\title{
Emotion regulation and internalizing symptoms in children with autism spectrum
} disorders

Carolien Rieffe, Paul Oosterveld, Mark Meerum Terwogt, Saskia Mootz, Edwin van Leeuwen and Lex Stockmann

Autism 2011 15: 655 originally published online 6 July 2011

DOI: $10.1177 / 1362361310366571$

The online version of this article can be found at:

http://aut.sagepub.com/content/15/6/655

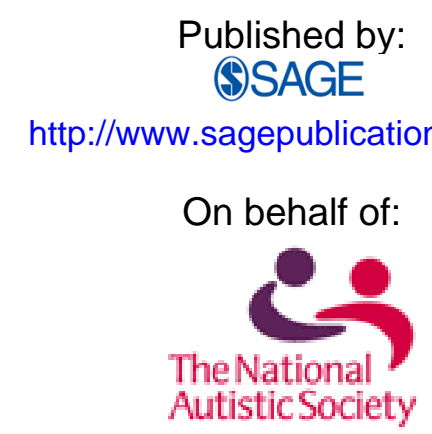

The National Autistic Society

Additional services and information for Autism can be found at:

Email Alerts: http://aut.sagepub.com/cgi/alerts

Subscriptions: http://aut.sagepub.com/subscriptions

Reprints: http://www.sagepub.com/journalsReprints.nav

Permissions: http://www.sagepub.com/journalsPermissions.nav

Citations: http://aut.sagepub.com/content/15/6/655.refs.html

>> Version of Record - Jan 18, 2012

OnlineFirst Version of Record - Jul 6, 2011 


\section{Emotion regulation and internalizing symptoms in children with autism spectrum disorders}

\author{
C A R O L I E N R I E F F E Leiden University, the Netherlands \\ PA U L O O S T E R V E L D Leiden University, the Netherlands \\ MARK MEERUM TERWOGT Free University, \\ the Netherlands
}

S A S K I A M O T Z Leiden University, the Netherlands

E DW I V V N L E E U E N Leiden University,

the Netherlands

L E X S T O C K M A N N Centre for Autism, Oegstgeest, the Netherlands

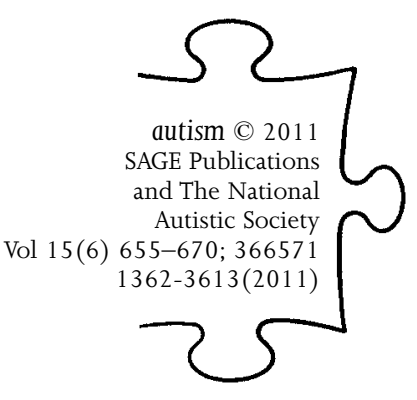

A BSTRACT The aim of this study was to examine the unique contribution of two aspects of emotion regulation (awareness and coping) to the development of internalizing problems in 11-year-old highfunctioning children with an autism spectrum disorder (HFASD) and a control group, and the moderating effect of group membership on this. The results revealed overlap between the two groups, but also significant differences, suggesting a more fragmented emotion regulation pattern in children with HFASD, especially related to worry and rumination. Moreover, in children with HFASD, symptoms of depression were unrelated to positive mental coping strategies and the conviction that the emotion experience helps in dealing with the problem, suggesting that a positive approach to the problem and its subsequent emotion experience are less effective in the HFASD group.

ADDRESS Correspondence should be addressed to: CAROLIEN RIEFFE, Leiden University, Developmental Psychology, Postbus 9555, 2300 RB Leiden, the Netherlands. e-mail:crieffe@fsw.leidenuniv.nl
KEYWORDS

alexithymia, adolescents, autism spectrum disorder, children, coping, depression, emotion awareness, health, rumination, somatic complaints, worry

Comorbidity of psychiatric symptoms in children with an autism spectrum disorder (ASD) is receiving increasing attention in the literature. Many studies focus on behavioural problems, such as ADHD or ODD (oppositional defiant disorder), which indeed occur more often than in a typically 
A U T IS M 15(6)

developing population (Gadow et al., 2008). Yet, there is also a growing interest in internalizing symptoms such as anxiety and depression in children with ASD (Kuusikko et al., 2008; Russell and Sofronoff, 2005; Simonoff et al., 2008), emphasising the importance of studying this phenomenon at an early stage. In typical development, there is a strong link between development of internalizing symptoms and emotion regulation, such that anxiety and depression are seen more commonly in those with poor emotion regulation. In this study, we focus on two key aspects of emotion regulation, emotion awareness and coping, and examine their associations with different internalizing symptoms in high functioning children with ASD.

\section{Emotion socialization}

Basic emotions set off functional response programs that serve to quickly adapt to changes in the environment (Levenson, 1999). Yet, a surfeit of emotions is dysfunctional, and is known to apply to many internalizing problems. A surfeit of emotions can be a dispositional (temperamental) issue, but it can also denote inadequate emotion regulation. In order to manage their initial emotion impulses, children are taught how to modify these in socially acceptable ways. This process of emotion socialisation starts at a very young age in typical development. Even in early day-care settings, children are taught how to react in a way that is acceptable to the social environment, yet without giving up their own interest. In other words, children learn how to find a balance between their own desires and needs on the one hand, and goals and demands from society on the other, without jeopardising social relationships or one's position in the ingroup. This requires a certain level of effortful emotion regulation. Two capacities within the domain of emotion regulation are especially important in dealing effectively with intense emotions and preventing emotion residues from turning into psychopathology: emotion awareness and coping strategies.

\section{Emotion regulation: emotion awareness}

A certain level of insight into one's own emotional responses and functioning is a prerequisite with respect to effective emotion regulation (Lambie and Marcel, 2002). This capacity is usually referred to as emotion awareness. Emotion awareness is defined by Rieffe, Oosterveld, Miers, Meerum Terwogt and Ly (2008) as an attentional process that serves to monitor and differentiate emotions, locate their antecedents, but ignore the physical arousal that is part of the emotion experience. Additionally, emotion awareness also includes attitudinal aspects, such as how emotion experiences are valued and should be expressed. 
The attentional component of emotion awareness shows conceptual overlap with the well-known concept of alexithymia. Core features of alexithymia that can also be established empirically can be best described as a limited ability to recognise and differentiate one's own emotions and verbalise them (see overview by Kooiman et al., 2002). These core features are also represented within the domain of emotion awareness. Several studies confirm that even in childhood, alexithymia and problems in the domain of emotion awareness are positively related to internalizing problems, such as depression, anxiety, somatic complaints, worry and rumination (Rieffe et al., 2006, 2008, 2010; Rieffe, Meerum Terwogt, Petrides, et al., 2007).

In addition to these outcomes based on self-report questionnaires, studies using other methods emphasise that a more advanced understanding of one's own emotions and talking about them are related to better emotion regulation or mental health (Barrett et al., 2001; Pennebaker, 1997). For example Barrett and colleagues offered participants nine affect terms, and asked them to rate their most intense emotion experience during that day, for 14 days, whereas Pennebaker used diary reports in various settings and across different time spans.

To date, not many studies have explicitly considered emotion awareness or alexithymia with respect to ASD. Few studies have administered selfreport questionnaires among adults with ASD, and found that the participants in the ASD group reported a higher degree of alexithymia than controls (Hill et al., 2004; Silani et al., 2008). Rieffe, Meerum Terwogt and Kotronopoulou (2007) presented children with ASD with a structured interview about their own emotion experiences. The outcomes of this study suggest that children with ASD not only have an impaired ability in differentiating between emotions, but are also impaired in locating the antecedents of their own emotion experience. These outcomes suggest problems with respect to the attentional component of emotion awareness in children with ASD.

With respect to the attitudinal component of emotion awareness, children with ASD might not fully appreciate the communicative value of emotional expressions, since they appear to express emotions incongruently, be less emotionally expressive in social situations, and address affect idiosyncratically rather than socially (Doussard-Roosevelt et al., 2003). Additionally, children with ASD are known to neglect emotional expressions of others (Begeer et al., 2006). The question is, however, the extent to which aspects of emotion awareness within children with ASD are associated with internalizing symptoms and whether this association is different from typical development. 
A U T IS M 15(6)

\section{Emotion regulation: mental coping strategies}

Coping refers to the attempts by the individual to diminish arousal during the emotion experience (Miers et al., 2007). Although the effectiveness of coping attempts depends on using the right strategy, by the right person, at the right moment, strategies that are based on mental activity - the so called cognitive strategies - are related particularly to internalizing problems (Fields and Prinz, 1997). For example, the ability for positive reappraisal is a strong predictor of fewer internalizing symptoms in children (Garnefski et al., 2007).

Few studies on coping or emotion regulation have been conducted with children with ASD. To our knowledge, only one study to date examined coping strategies in ten-year-old children with ASD by means of vignettes describing stressful daily life events. Children were asked how they would feel and if there would be anything they could do to feel less angry or sad, depending on the emotion they had given. From this study it appeared that children with ASD mentioned fewer cognitive coping strategies than the controls in order to deal with common daily negative life events, such as a new watch that breaks (Rieffe et al., 2003). Yet, it remains unclear to what extent a possible lack of adaptive cognitive strategies in children with ASD is associated with internalizing symptoms.

\section{Current study}

In typically developing children, it has become evident that impairments in emotion regulation are related to more internalizing symptoms. First, findings regarding emotion awareness, a primary step in adaptive emotion regulation, and its evident link with internalizing symptoms, support this relation. Second, empirical studies also demonstrate that maladaptive cognitive coping strategies are positively associated with internalizing symptoms in children, whereas the reverse applies to adaptive strategies. In this study, we want to confirm these relationships of a) emotion awareness and b) cognitive coping strategies with internalizing symptoms, by comparing the extent to which the relationships between these variables as presented in typically developing children also apply to high-functioning children with ASD.

The internalizing symptoms that were included in this design concern frequently studied symptoms in typically developing children with respect to emotion awareness and coping: depression, somatic complaints and worry/rumination. Although anxiety is a common symptom in children with ASD, it was not included in this particular study because of its high statistical intercorrelation with both depression and worry. Many studies of internalizing symptoms in children with ASD are based on parents' reports. However, the best source of information about their own internal states is 
the children themselves (Rieffe et al., 2008). Therefore, this study is based on children's self-reports, following a study on individuals with an ASD by Hill, Berthoz and Frith (2004). The age range of 10 to 12 years was chosen, because at this age children are increasingly able to reflect upon their own internal states and emotions (Harris, 1989).

The study focuses on the relationship between two aspects of emotion regulation (emotion awareness and coping) and internalizing symptoms (depression, somatic complaints and worry/rumination) in typically developing children and those with ASD and the moderating effect of group membership on this relation. These relations are established through regression analysis. The analysis framework chosen here is multi-group structural equation modeling (SEM), as this allows statistical testing equality of regression parameters for different groups (Bollen, 1989).

\section{Method}

\section{Participants and procedure}

A total of 184 children participated in this study. The sample included 66 high-functioning children with autism (58 boys, 8 girls - mean age 11 years, 5 months; SD $=10.1$ months; range 119-154 months), with a diagnosis based on the Autism Diagnostic Interview-Revised (Lord et al., 1994) by child psychiatrists from the Centre for Autism, Oegstgeest, the Netherlands, which is one of the main specialist centres for autism in the Netherlands and diagnoses approximately 800 children and adolescents between 1 and 18 years old per year. Additionally, the Centre for Autism is frequently consulted by other, more general child psychiatric institutes.

The ASD participants in our study met the diagnostic criteria for ASD from the DSM-IV (American Psychiatric Association, 1995), and were recruited via the Centre for Autism. A total of 110 children were approached of which 67 returned the home-sent questionnaires (60.9\%). The data of one participant was excluded from the data-set, because his data showed more than 10 missing values. The mean verbal IQ (WISC-R) for the ASD group was 107.0, SD 14.81, with all individuals scoring $>80$.

A control group $(n=118-104$ boys, 14 girls - mean age 11 years, 5 months; SD $=7.9$ months; range 123-155 months) was drawn from primary schools in the Netherlands. This group was matched with the clinical group on mean age and the ratio of boys to girls. Questionnaires were handed out in the classroom by the experimenter. Children in this group functioned at an adequate level in regular elementary schools and showed intelligence within the normal range according to the Dutch national educational system, which provides outplacement to special 
A U T IS M 15(6)

education institutes for children with learning difficulties (Driessen, 2002). Parental consent was obtained prior to the data collection for all participants. In addition to the child questionnaires, parents were also asked to fill out questionnaires about their child.

\section{Materials}

Child reports. The Children's Depression Inventory (CDI; Kovacs, 1985) contains 26 items, each of which consists of 3 statements which are assumed to reflect aspects of depression in different degrees. The participants are asked to select the statement that best describes their feelings in the past two weeks (e.g. 'Nobody really loves me'; 'I am not sure if anybody loves me'; 'I am sure that somebody loves me').

The Somatic Complaint List (SCL; Rieffe, Meerum Terwogt, Petrides, et al., 2007; Rieffe et al., 2008) consists of 11 items. Participants have to rate on a 5 -point response scale $(1=$ never, $2=$ almost never, $3=$ sometimes, 4 $=$ often, $5=$ very often) the frequency with which they experience certain bodily complaints, such as a stomach-ache. The scoring is reversed for two items which were formulated positively, for example "I never/sometimes/ often feel well".

The Worry/Rumination Questionnaire for Children (Rieffe, Meerum Terwogt, Petrides, et al., 2007; Rieffe et al., 2008) reflects the tendency to dwell on a problem instead of dealing with it in terms of solving or coping adaptively with the emotional impact of the situation (e.g. "When I have a problem, I cannot stop thinking about it"). The questionnaire comprises 10 items. Respondents are asked to rate the degree to which each item is true about them on a 3 -point response scale $(1=$ not true, $2=$ sometimes true, $3=$ often true). The scoring is reversed for 1 item.

The Emotion Awareness Questionnaire (EAQ30; Rieffe et al., 2008) aims to identify how children and adolescents feel and think about their feelings. The EAQ (30 items of which 20 items are negatively formulated and thus reversed-scored) was designed with a 6-factor structure describing six aspects of emotional functioning: (1) Differentiating Emotions (e.g. 'When I am upset, I don't know if I am sad, scared or angry', reversed-scored), (2) Verbal Sharing of Emotions (e.g., 'I can easily explain to a friend how I feel inside'), (3) Not Hiding Emotions (e.g., 'When I am upset, I try not to show it', reversed-scored), (4) Bodily Awareness of Emotions (e.g. 'When I feel upset, I can also feel it in my body', reversed-scored), (5) Attending to Others' Emotions (e.g., 'If a friend is upset, I try to understand why'), and (6) Analyses of Emotions (e.g. 'My feelings help me to understand what has happened'). Respondents are asked to rate the degree to which each item is true about them on a three-point scale $(1=$ not true, 
$2=$ sometimes true, $3=$ often true). In all the scales, a higher score represented a higher presence of this ability, with the exception of Bodily Awareness, in which a higher score implicates less attention to bodily symptoms. The scales have good internal consistencies (Rieffe et al., 2008, 2009).

The Coping Questionnaire (Cognitive Emotion Regulation Questionnaire for Kids; Garnefski et al., 2007) aims to identify the frequency with which children employ certain thoughts which are assumed to change the emotional impact of an event. The questionnaire consists of 36 items, 16 items representing Adaptive Coping Strategies, such as planning and acceptance (e.g. 'I think of what would be the best for me to do') and 20 items representing Maladaptive Coping Strategies, such as catastrophizing and selfblame (e.g. 'I think that I have been stupid'). The instruction was "When you experience negative or unpleasant events. ." and the 36 items followed, which could be scored on a 5 -point scale indicating how often the respondent had each thought.

Parent report. The Strengths and Difficulties Questionnaire (SDQ, Goodman, 1997; Dutch validation by Muris, Meesters, and van den Berg, 2003) is a brief measure of the adjustment and psychopathology of children and adolescents. The questionnaire consists of 25 items in which parents are asked to indicate on a 3-point response scale the extent to which their child shows symptoms of emotional maladjustment, behavioral problems, hyperactivity, attention problems, problems with peers and a lack of prosocial behavior ( $1=$ not true, $2=$ somewhat true, $3=$ certainly true). For this study, we only used the scale Emotional (5 items, e.g. "Often unhappy, down-hearted or tearful").

All questionnaires show good internal consistencies in both groups (Table 1). Additionally, Table 1 shows higher mean scores for children with ASD on Bodily Symptoms (EAQ) and the SDQ, but lower scores on Adaptive Coping in comparison to their typical peers, highlighting difficulties in these domains.

\section{Analyses}

The relations between the variables were established by means of regression analyses. Internalizing symptoms were the dependent variables, and aspects of emotion regulation the independent. Equally important as the strength of the relations are the differences between them in the two samples. This was tested by taking a multigroup approach to regression analysis, which can be realized by means of Structural Equation Modeling (SEM). In such an approach, first a model is tested with equality restrictions on the regression parameters over the groups (i.e. the matrices of 
Table I Psychometric properties of the questionnaires for Depressive Symptoms, Somatic Complaints, Worry/Rumination, Coping and Emotion Awareness

\begin{tabular}{|c|c|c|c|c|c|}
\hline & \multirow{2}{*}{$\begin{array}{l}\text { Number } \\
\text { of items }\end{array}$} & \multicolumn{2}{|c|}{ Cronbach's alpha } & \multicolumn{2}{|c|}{ Mean scores } \\
\hline & & $A S D$ & Control & $A S D$ & Control \\
\hline Depression & 26 & .76 & .82 & $1.35(.19)$ & $1.39(.24)$ \\
\hline Somatic Complaints & 11 & .80 & .80 & $\mathrm{I} .92(.53)$ & $2.03(.60)$ \\
\hline Worry/Rumination & 10 & .81 & .83 & $1.93(.42)$ & $1.91(.45)$ \\
\hline \multicolumn{6}{|l|}{ EAQ scales } \\
\hline Differentiating & 7 & .79 & .64 & $2.39(.47)$ & $2.42(.36)$ \\
\hline Verbal Sharing & 3 & .82 & .68 & $1.96(.68)$ & $2.04(.58)$ \\
\hline Not Hiding Emotions & 5 & .57 & .61 & $1.92(.45)$ & $1.96(.44)$ \\
\hline Bodily Awareness** & 5 & .73 & .65 & $2.19(.55)$ & $1.97(.49)$ \\
\hline Others' Emotions & 5 & .76 & .74 & $2.28(.50)$ & $2.25(.49)$ \\
\hline Analyses Emotions & 5 & .80 & .76 & $\mathrm{I} .94(.59)$ & $2.02(.52)$ \\
\hline \multicolumn{6}{|l|}{ Coping strategies } \\
\hline Adaptive* & 20 & .82 & .85 & $2.50(.63)$ & $2.71(.64)$ \\
\hline Maladaptive & 16 & .70 & .82 & $2.21(.52)$ & $2.24(.58)$ \\
\hline SDQ, emotionality Parent Form** & 5 & .68 & .71 & $\mathrm{I} .83(.47)$ & $\mathrm{I} .36(.42)$ \\
\hline
\end{tabular}

$* p<.05 ; * * p<.01$.

Note. ASD = autism spectrum disorder; EAQ = Emotion Awareness Questionnaire (Rieffe et al., 2008);

SDQ = Strengths and Difficulties Questionnaire (Goodman, 1997).

regression parameters contain exactly the same values). Model fit can be evaluated by means of a chi-square test and several fit indices such as the Root Means Square Error of Approximation (RMSEA). If the test statistic reaches significance, the null hypothesis of equal regression parameters must be rejected. A problem with the exact test is that minor misspecifications may lead to rejection of the model. Therefore, fit measures as the root mean square error of approximation (RMSEA) should also be taken into account. The RMSEA should not exceed the .08 level. If the null hypothesis of model fit is rejected, univariate tests of specific parameters (the so-called modification indices) can be used to identify the specific differences. If the two sets of regressions parameter indeed differ, group membership had a moderating effect on the relation between the variables.

\section{Results}

\section{Emotion awareness}

Table 2 shows the regression coefficients for the EAQ scales in both groups. The $R^{2}$ values are moderately high for the CDI, SCL and Worry/Rumina- 
tion Questionnaire $(.22, .21, .35$, respectively). It can be seen that Differentiating Emotions and Bodily Awareness contribute to explaining variance in all dependent variables. Additionally, Analyses Emotions contributes significantly to explaining variance in Depression (CDI), whereas the scale Verbal Sharing contributes significantly to explaining variance in Somatic Complaints (SCL) and Worry/Rumination.

The equality of this regression model of the EAQ scales on the CDI, SCL, and Worry scales was tested with a multi-group analysis with equality constraints on all parameters. The chi-square reached significance $\left(\chi^{2}=\right.$ 76.19 , $\mathrm{df}=45, \mathrm{p}<.002)$, and also other fit measures show violations of equality (RMSEA $=.084$; GFI $=.87$ ), suggesting a misfit. This indicates that there are significant differences in the parameters between the two groups. The modification indices implied that removing the equality restriction in the regression of Depression on Analyses Emotion; in the regression of Somatic Complaints on Others' Emotions and Analyses Emotions; and in the regression of Worry/Rumination on Not Hiding, Bodily Symptoms and Analyses Emotions will result in the largest decreases in chi-square value. The regression coefficients indicated a stronger negative contribution in the control sample than in the ASD sample for Analyses Emotions concerning Depression and for Bodily Symptoms concerning Worry/Rumination. Analyses Emotions will only contribute positively to Worry/Rumination in the control sample, whereas this is true for Not Hiding in the ASD sample. Two scales, Others' Emotions and Analyses Emotions, that also indicated differences between the two groups if the equality restriction were removed for Somatic Complaints, show no significant contributions for either group.

\section{Coping strategies}

The correlations and the regression coefficients for the internalizing symptoms (CDI, SCL and Worry/Rumination) and the two Coping Strategies are presented in Table 3. As expected, internalizing symptoms correlate positively with Maladaptive Coping Strategies and negatively with Adaptive Coping Strategies. The equality of regression models of the Mood scales on the CDI, SCL, and Worry scales was tested with a multi-group analysis. The chi-square reached significance $\left(\chi^{2}=17.68, \mathrm{df}=8, \mathrm{p}<.041\right)$, and also other fit measures showed a misfit between the two groups (RMSEA $=$ .088 ; GFI $=.93)$. The expected decrease in chi-square value would result from releasing the equality constraint on Adaptive Coping Strategies: the regression coefficient will have a negative contribution concerning Depression in the control group but not the ASD group. No differences were found regarding the Maladaptive Coping Strategies. The $R^{2}$ values are moderately high for CDI and Worry/Rumination Questionnaire (.18 and .36, respectively), but lower for SCL (.09). 


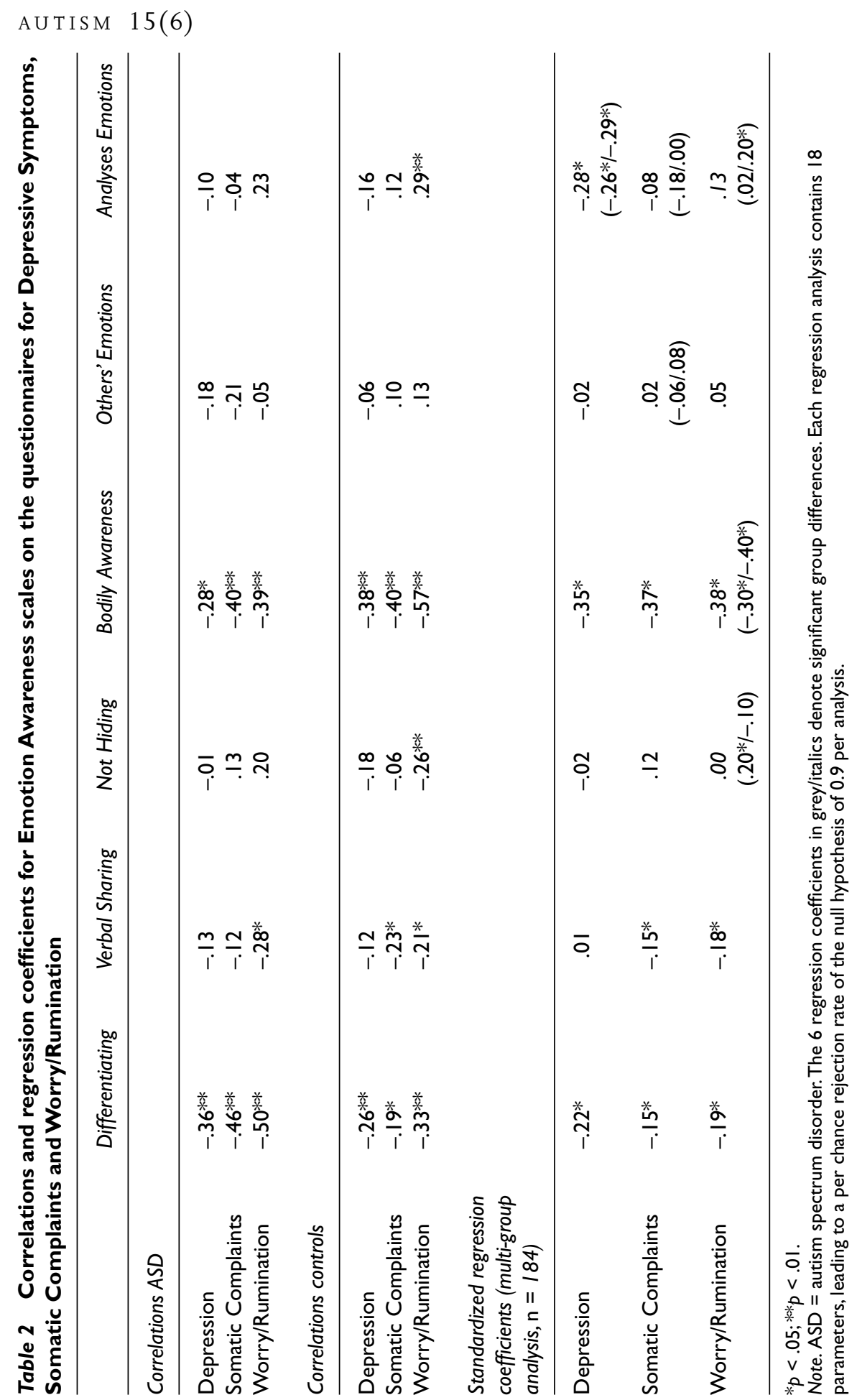

664 
Table 3 Correlations and regression coefficients for Coping on the questionnaires for Depressive Symptoms, Somatic Complaints and Worry/Rumination

\begin{tabular}{lll}
\hline & \multicolumn{1}{l}{ Coping Strategies } & \\
\cline { 2 - 3 } & Adaptive & Maladaptive \\
\hline Correlations ASD & \\
\cline { 2 - 2 } Somatic Complaints & -.12 & $.40^{* *}$ \\
Worry/Rumination & $-.28^{*}$ & .24 \\
& $-.28^{*}$ & $.56^{* *}$ \\
Depression & Correlations controls & \\
Somatic Complaints & $-.23^{*}$ & $.32^{* *}$ \\
Worry/Rumination & -.11 & $.26^{* *}$ \\
& -.06 & $.53^{* *}$ \\
& Standardized regression coefficients & \\
\hline Depression & $-.11 *$ & $.17^{*}$ \\
Somatic Complaints & $\left(-.04 /-.15^{*}\right)$ & $.34^{*}$ \\
Worry/Rumination & $-.23^{*}$ & $.48^{*}$ \\
\hline
\end{tabular}

$* p<.05 ; * * p<.01$.

Note. $\mathrm{ASD}=$ autism spectrum disorder.

\section{Discussion}

The central aim of this study was to examine the extent to which the two different aspects of emotion regulation, awareness and cognitive coping strategies, are associated with internalizing symptoms in high-functioning children with ASD, compared to a typically developing control group. It should first be noted that the parents of the ASD group indeed identified more emotional problems than the parents in the control group. The ASD children, however, did not seem to note more emotional problems than their typically developing peers (except for fewer adaptive coping strategies) by means of self-report questionnaires. Nevertheless, in line with an earlier study also using this method (Hill et al., 2004), the internal consistency and validity of the self-report scales were good in both groups.

The analyses with respect to our research question concerning the prediction of internalizing symptoms indeed showed differences between both groups, implying a moderating effect of group. Overall, it should first be noted that most explained variances are satisfactory in both regression 
models, signifying the importance of these models. With respect to the various aspects of emotion awareness, the ability to differentiate between various emotions, identify their causes, communicate them to others, and the tendency to ignore bodily arousal during the emotion experience all contributed negatively to the prediction of internalizing symptoms in both groups, conforming with previous studies (Rieffe, Meerum Terwogt, Petrides, et al., 2007; Rieffe et al., 2008).

Yet, the tendency to ignore physiological signals during the emotion experience made a stronger contribution for the control group in the prediction of worry and rumination. Moreover, it can be observed that the willingness to value emotions as an important source of information that might help someone to understand their own problems contributed more strongly to the prediction of symptoms of depression for the control group. Note that 'Analyses of Own Emotions' was related positively to symptoms of worry and rumination in the typically developing population in previous studies (Rieffe et al., 2008). This outcome was confirmed in this study. However, the most striking difference between the two groups with respect to emotion awareness was the positive contribution of 'Not-Hiding' for children with ASD to the prediction of worry and rumination, whereas this aspect failed to contribute in the case of the control group.

With respect to children's coping strategies, it appeared that maladaptive strategies contributed positively to all internalizing symptoms, as did adaptive strategies negatively, except for adaptive coping strategies in the clinical group. Only in children with ASD did adaptive coping strategies fail to contribute to the prevention of depressive symptoms.

Based on these results, we first want to note that the regression models in both groups show substantial overlap, especially with respect to the three variables that also contributed most strongly to internalizing symptoms in various studies in the past which mainly concern the attentional part of emotion awareness. This seems to confirm other studies also indicating that the development of internalizing symptoms in children with ASD does indeed follow qualitatively similar causal pathways compared to typically developing children (Lecavalier et al., 2009). Nevertheless, testing both regression models on their equality showed a significant difference. Thus the results show that there are three important differences between the two groups that need further elaboration and discussion.

First, the results in this study showed that two aspects of emotion awareness contributed less strongly or not at all to the prediction of internalizing symptoms in children with ASD compared to the control group: a) the acknowledgement or attitude that emotions provide important information in helping to analyse a problem ('Analyses Emotions') and b) the awareness that bodily symptoms occur during an emotion arousal 
('Bodily Awareness'). It is argued that - in typical development - lesser acknowledgement of emotions as an important source of information contributes to symptoms of depression, because these children fail to analyse emotion-evoking situations well enough to deal with them adaptively but instead are more inclined to ignore this kind of information. This might contribute to a surfeit of emotions which, in turn, can develop into a mood disorder. However, too much attention to the value of emotions can cause non-productive circular thoughts, such as worry and rumination. Too much attention to bodily symptoms can further contribute to this. In fact, focusing on internal signals might be at the expense of concentrating on the external cause, the emotion-evoking situation. This also implies that children who pay too much attention to physiological arousal fail to see these physiological symptoms as an integrated part of the emotion experience, which will automatically vanish once the emotion evoking situation is dealt with adaptively (Rieffe et al., 2006; Rieffe, Meerum Terwogt, Petrides, et al., 2007).

The fact that in children with ASD especially these two aspects of emotion awareness contribute less strongly to the prediction of one or more internalizing symptoms seems to suggest that these children have a more fragmented understanding of emotions and their own emotion experience. In other words, these outcomes suggest that children with ASD seem more inclined to observe the elements of an emotion experience which, in fact, form an integrated whole that cause the individual to react quickly and adaptively to the environment - as separate issues and not necessarily interdependent.

Second, it appeared that the tendency to hide their own emotions from others contributed less strongly to the prediction of worry and rumination in children with ASD. This suggests a certain level of self understanding in ASD children with respect to their frequently noted impairment to express emotions adequately (Barbaro and Dissanayake, 2007). Obviously, it is better to keep your emotions to yourself if you think you are unable to express them in a way that is useful to obtain your goals, yet without risking or harming the relationship.

Third, the finding that adaptive cognitive coping strategies failed to contribute to the prediction of depressive symptoms in children with ASD could be in line with an earlier study showing that children with ASD spontaneously mentioned fewer cognitive coping strategies to improve their negative mood state (Rieffe et al., 2003). In the present study, children did not have to spontaneously think of strategies, but instead, they were presented with strategies to which they could denote how often they would apply this specific thought. Yet, given the outcome of the regression model, it seems that positive thoughts worked less well for children with 
ASD with respect to their depressive symptoms, which indicate a long lasting surfeit of negative emotions. Nevertheless, these positive thoughts seemed to contribute to fewer somatic complaints and fewer worries.

Although only a longitudinal design can confirm the causality of these relationships, at this point we were merely interested in the extent to which these commonly found patterns in typical development indeed affect children with ASD. Overall, the findings of this study suggest that a more fragmented orientation with respect to the various aspects of the emotion experience contributes specifically to more worry and rumination in highfunctioning children with ASD, whereas symptoms of depression seem to be related to a reduced attitude or ability to positively approach the problem and the related emotion experience. In the near future, we hope to further confirm and elaborate on these findings and also include other symptoms of internalizing problems, such as anxiety, in a longitudinal design which will enable us to examine causality of the relationships between these variables.

Note that the reliability of self-report questionnaires for children is sometimes questioned. However, emotion experience and internalising symptoms are internal processes to which only respondents have direct access (Barrett et al., 2007; Lambie and Marcel, 2002). Thus, instead of drawing from other sources of information, it might be more sensible to ask children themselves. Furthermore, it has frequently been shown that children are better informants than parents or teachers with respect to their own internalizing symptoms (Achenbach et al., 1987; DiBartolo and Grills, 2006), which also emphasizes the validity of using self-report methods, even in children. The extent to which this also applies to high-functioning children with an ASD is still unclear. The good internal consistencies of the scales in this study do not prove but do support the assumption that this particular group is capable of responding coherently to self-report questionnaires about their own inner states.

\section{Acknowledgements}

The authors would like to thank Elisabeth Hill for her comments on an earlier draft of this manuscript, and Anna Brett for correcting our English. However, any possibly remaining errors are the authors' sole responsibility. This research was supported by the Innovational Research Incentives Scheme (a VIDI grant) by The Netherlands Organisation for Scientific Research (NWO), no. 452-07-004 to Carolien Rieffe.

\section{References}

Achenbach, T.M., McConaughy, S.H. \& Howell, C.T. (1987) 'Child Adolescent

Behavioral and Emotional-Problems - Implications of Cross-Informant

Correlations for Situational Specificity', Psychological Bulletin 101: 213-232. 
American Psychiatric Association (1995) Diagnostic and Statistical Manual of Mental Disorders (4th ed). Washington, DC: Author.

Barbaro, J. \& Dissanayake, C. (2007) 'A Comparative Study of the Use and Understanding of Self-Presentational Display Rules in Children with High Functioning Autism and Asperger's Disorder', Journal of Autism and Developmental Disorders 37: 1235-1246.

Barrett, F.L., Gross, J., Christensen, T.C. \& Benvenuto, M. (2001) 'Knowing What You're Feeling and Knowing What to Do About It: Mapping the Relation between Emotion Differentiation and Emotion Regulation', Cognition and Emotion 15: 713-724.

Barrett, F.L., Mesquita, B., Ochsner, K.N. \& Gross, J. (2007) ‘The Experience of Emotion', Annual Review of Psychology 58: 373-403.

Begeer, S., Rieffe, C., Meerum Terwogt, M. \& Stockmann, A.P.A.M. (2006) 'Attention to Facial Emotion Expressions in Children with Autism’, Autism 10: 37-51.

Bollen, K. (1989) Structural Equations with LatentVariables. New York: Wiley.

DiBartolo, P.M. \& Grills, A.E. (2006) 'Who is Best at Predicting Children's Anxiety in Response to a Social Evaluative Task? A Comparison of Child, Parent, and Teacher Reports', Journal of Anxiety Disorders 20: 630-645.

Driessen, G. (2002) 'School Composition and Achievement in Primary Education: A Large-Scale Multilevel Approach’, Studies in Educational Evaluation 28: 347-68.

Doussard-Roosevelt, J.A., Joe, C.M., Bazhenova, O.V. \& Porges, S.W. (2003) 'Mother-Child Interaction in Autistic and Nonautistic Children: Characteristics of Maternal Approach Behaviours and Child Social Responses', Development and Psychopathology 15: 277-295.

Fields, L. \& Prinz, R.J. (1997) 'Coping and Adjustment during Childhood and Adolescence’, Clinical Psychology Review 17: 937-976.

Gadow, K.D., DeVincent, C.J. \& Drabick, D.A.G. (2008) 'Oppositional Defiant Disorder as a Clinical Phenotype in Children with Autism Spectrum Disorder', Journal of Autism and Developmental Disorders 38: 1302-1310.

Garnefski, N., Rieffe, C., Jellesma, F., Meerum Terwogt, M. \& Kraaij, V. (2007) 'Cognitive Emotion Regulation Strategies and Emotional Problems in 9-11-Year-Old Children: The Development of an Instrument. European Child \& Adolescent Psychiatry 16: 1-9.

Goodman, R. (1997) 'Psychometric Properties of the Strengths and Difficulties Questionnaire', Journal of the American Academy of Child \& Adolescent Psychiatry 40: 1337-1345.

Harris, P.L. (1989) Children and Emotions: The Development of Psychological Understanding. Cambridge: Basil Blackwell.

Hill, E., Berthoz, S. \& Frith, U. (2004) 'Brief Report: Cognitive Processing of Own Emotions in Individuals with Autistic Spectrum Disorder and in Their Relatives', Journal of Autism and Developmental Disorders 34: 229-235.

Kooiman, C.G., Spinhoven, P. \& Trijsburg, R.W. (2002) 'The Assessment of Alexithymia - A Critical Review of the Literature and a Psychometric Study of the Toronto Alexithymia Scale-20', Journal of Psychosomatic Research 53: 1083-1090.

Kovacs, M. (1985) 'The Children's Depression Inventory (CDI)', Psychopharmacology Bulletin 21: 995-998.

Kuusikko, S., Pollock-Wurman, R., Jussila, K., Carter, A.S., Mattila, M. L., Ebeling, H., Pauls, D.L., \& Moilanen, I. (2008) 'Social Anxiety in High-Functioning Children and Adolescents with Autism and Asperger Syndrome', Journal of Autism and Developmental Disorders 38: 1697-1709. 
Lambie, J.A. \& Marcel, A.J. (2002) 'Consciousness and the Varieties of Emotion Experience: A Theoretical Framework’, Psychological Review 109: 219-259.

Lecavalier, L., Gadow, K.D., DeVincent, C.J. \& Edwards, M.C. (2009) 'Validation of DSM-IV Model of Psychiatric Syndromes in Children with Autism Spectrum Disorders', Journal of Autism and Developmental Disorders 39: 278-289.

Levenson, R.W. (1999) 'The Interpersonal Functions of Emotion', Cognition and Emotion 13(5): 481-504.

Lord, C., Rutter, M. \& Le Couteur, A. (1994) 'Autism Diagnostic Interview-Revised A Revised Version of a Diagnostic Interview for Caregivers of Individuals with Possible Pervasive Developmental Disorders', Journal of Autism and Developmental Disorders 24: 659-685.

Miers, A.C., Rieffe, C., Meerum Terwogt, M., Cowan, R. \& Linden, W. (2007) 'The Relation between Anger Coping Strategies, Anger Mood and Somatic Complaints in Children and Adolescents', Journal of Abnormal Child Psychology 35: 653-664.

Muris, R., Meesters, C., van den Berg, F. (2003) 'The Strengths and Difficulties Questionnaire (SDQ). Further Evidence for Its Reliability and Validity in a Community Sample of Dutch Children and Adolescents', European Child \& Adolescent Psychiatry 12: 1-8.

Pennebaker, J.W. (1997) 'Writing About Emotional Experiences As A Therapeutic Process', Psychological Science 8: 162-166.

Rieffe, C., Meerum Terwogt, M. \& Kotronopoulou, K. (2007) 'Awareness of Single and Multiple Emotions in High-Functioning Children with Autism', Journal of Autism and Developmental Disorders 37: 455-465.

Rieffe, C., Meerum Terwogt, M., Petrides, K.V., Cowan, R., Miers, A.C. \& Tolland, A. (2007) 'Psychometric Properties of the Emotion Awareness Questionnaire for Children', Personality and Individual Differences 43: 95-105.

Rieffe, C., Oosterveld, P. \& Meerum Terwogt, M. (2006) 'An Alexithymia Questionnaire for Children: Factorial and Concurrent Validation Results', Personality and Individual Differences 40: 123-133.

Rieffe, C., Oosterveld, P., Meerum Terwogt, M., Novin, S., Nasiri, H. \& Latifian, M. (2010) 'Relationship between Alexithymia, Mood and Internalizing Symptoms in Children and Young Adolescents: Evidence from an Iranian Sample', Personality and Individual Differences 48: 425-430.

Rieffe, C., Oosterveld, P., Miers, A.C., Meerum Terwogt, M., Ly, V. (2008) 'Emotion Awareness and Internalizing Symptoms in Children and Adolescents: The Emotion Awareness Questionnaire Revised', Personality and Individual Differences 45: 756-761.

Rieffe, C., Triantafyllakos, A. \& Meerum Terwogt, M. (2003) 'La gestion des emotions negatives chez les enfants autistes de haut niveau', Le Bulletin Scientifique de l'ARAPI 11: 35-36.

Russell, E. \& Sofronoff, K. (2005) 'Anxiety and Social Worries in Children with Asperger Syndrome’, Australian and New Zealand Journal of Psychiatry 39: 633-638.

Silani, G., Bird, G., Brindley, R., Singer, T., Frith, C. \& Frith, U. (2008) 'Levels of Emotional Awareness and Autism: An fMRI Study’, Social Neuroscience 3: 97-112.

Simonoff, E., Pickles, A., Charman, T., Chandler, S., Loucas, T. \& Baird, G. (2008) 'Psychiatric Disorders in Children with Autism Spectrum Disorders: Prevalence, Comorbidity, and Associated Factors in a Population-Derived Sample', Journal of the American Academy of Child and Adolescent Psychiatry 47: 921-929. 